\title{
"These cameras are here for a reason" - media coming out, symbolic power and the value of 'participation'. Behind the scenes of the Dutch reality programme Uit de Kast
}

\author{
Balázs Boross \\ Erasmus University Rotterdam
}

Stijn Reijnders

Erasmus University Rotterdam

The final, definitive version of this paper has been published in Media, Culture \& Society, online first, April 18, 2016 as doi:10.1177/0163443716643152 by SAGE Publications Ltd

http://mcs.sagepub.com/content/early/2016/04/18/0163443716643152.abstract

\begin{abstract}
This paper addresses the increasing popularity of coming out as mediatized practice, by focusing on the example of the internationally successful Dutch television programme Uit de Kast ('Out of the Closet'). While the choice of coming out in front of the cameras is often received controversially both by the public and the protagonists' immediate environment, youngsters keep applying to participate in the programme. To understand the continuous appeal of this form of self-disclosure, in-depth interviews were conducted with ten participants from different seasons about their motivations, experiences and evaluations of taking part in the show. By following their journey into the world of media production, this paper highlights the implications of media participation for the process of coming out, as related to questions of empowerment, visibility and agency, and ultimately, to the perceived symbolic value of (participating in) broadcast media in the new media age.
\end{abstract}

Key words: media participation, coming out, symbolic power, agency, factual entertainment, ritual

\section{Introduction}

My father saw that I was really nervous, so he broke the silence: 'So Theo, what are your plans for your trip around the world?' But I wished he hadn't asked that: there will be too much emphasis on the story of the travelling, and getting out of the lie will be even harder. So I looked at the directors.

There were many people around: two cameramen, two audio people, two directors, and the presenter, Arie. Our dining room was crowded. I looked at the directors and they were looking like 
'you have to do it yourself'. Then one of the directors realized that my mom was still in the kitchen. So she ran into the kitchen to get my mom. I hadn't even noticed. I was that nervous.

She took her place and she was like 'I am on television, so I put up a smile'. And I was already saying the words 'I am into guys'. And I never saw my mom like that, but... her smile was like frozen. And then my father was looking at the cameras, and he was like 'fuck, what the hell is happening'. Then he looked at my mom who was still smiling. He thought she was part of it, that she knew it. He got really angry and disappointed.

This quote refers to a critical moment of the shooting of an episode of Uit de Kast, the popular Dutch television programme in which 'ordinary' youngsters come out 'live' to their unsuspecting friends and relatives, narrated by the protagonist Theo during an almost three hour long conversation, as part of a series of ten interviews with participants about their experiences of taking part in the show. Although Theo was an early candidate - his episode was aired in the first season, and the programme recently entered into its fourth year - the recollection of his memories was unexpectedly vivid and intense.

As demonstrated not only by the ubiquity of live coming out videos on the internet ${ }^{1}$, but also by the continuous success of this televised format, using the media to disclose one's sexual identity has become a booming phenomenon in recent years. Uit de Kast, this hybrid of educational, documentary public service programming and surveillance entertainment, appears not to have a shortage of candidates: the show, originally produced by the Dutch public broadcaster KRO, was later taken over by the Belgian commercial channel VTM. This ongoing appeal to the practice of media(ted) coming out raises a simple but intriguing question: why do young people, one after another, choose to come out in front of the cameras, even if this decision may, as the above quote demonstrates, also backfire? And why do parents finally give consent to broadcasting these tense, contradictory moments?

This mediated confessional practice, at least on the textual level of Uit de Kast, is legitimized and justified in various ways. As argued elsewhere (author removed, 2015), this legitimacy is largely based on structuring, presenting and narrating the self-disclosure as a patterned and culturally meaningful performance - a contemporary rite of passage. It also appears that due to the guiding and mediating assistance of the presenter, the endeavour ultimately brings the parties closer to each other: by the closing scenes of the episodes, both the protagonists and the attitudes of their environment are transformed. As can be suggested, this reinforcement of the programme's indispensable role in governing the coming out process not only serves to (re)affirm wider claims about media's authority to represent and change social reality, but also naturalizes what we have previously called the myth of participation: the pervasive assumption, increasingly nourished and maintained by media institutions, that media participation is a particularly effective means to create order in everyday, ordinary lives (author removed, 2015).

This paper offers a look behind the scenes - and beyond the screen. Departing from the representation of coming out as a mediated ritual practice towards the examination of how this media ritual is actually experienced by the participants, we ask how the perceived symbolic power of media is appropriated, challenged or reproduced throughout the 
participants' simultaneous journey into the world of media production, out of the closet - and back to 'ordinary' life. In doing so, we aim, on the one hand, to capture how assumptions about media as a privileged and particularly efficient site of managing the social world is constructed, internalized and acted out in the off-screen realm of media production. On the other hand, we ask what values are actually attached to participation by those from whom the action is originated. By taking such an ethnographic perspective, we hope not only to deliver a contextualized account of the relationship between agency and the regulative power of the media, but also to further enhance our understanding of the complex ways media practice anchors other social practices (cf. Swidler, 2001; Hobart, 2010; Couldry, 2012) - in our case, to grasp what the implications of acting for television are for the process of coming out.

To unpack these issues, the following sections will trace the subtle mechanisms through which the participants' journey from complete secrecy to media publicity is experienced and carried out. We will demonstrate that this process is primarily based on the interplay of two - seemingly conflicting - yet in the end complementary desires: on the one hand, the longing for absorbing oneself in a higher (media) logic and, on the other hand, gaining the ability to utilize the power of the media for one's own agency and interests. By presenting and analysing 1 ) the candidates' narratives about their expectations and motivations for joining the programme, 2) their experiences of being part of the production, and 3) the afterlife of their disclosure, we shall also highlight how the particularities of media coming out are linked to more general questions of the production of 'ordinariness', notions of authenticity and empowerment, and ultimately, to the perceived symbolic value of (participating in) broadcast media in the new media age. But before turning our attention to the candidates' journey, we briefly summarize the core theoretical considerations and methods that informed our analysis.

\section{Media participation as ritual practice}

The past decades have witnessed an increasing visibility of 'ordinary' people in the media, partly through the proliferation of - often controversial - formats based on 'true' experiences and emotions of non-professional participants. The reality trend, with all its incarnations, has resulted in important debates concerning the broader consequences of the 'demotic turn' (Turner, 2010) and its ethos of participation, revolving around questions of empowerment, the democratization of media production, exploitation and ethics (cf. Dovey, 1998; Andrejevic, 2004; Schafer, 2011; Couldry, 2012).

Still, while there is a strong tradition of addressing the role of participants in the political economy of the industry (cf. Curnutt, 2011), empirical research into the actual experiences of taking part in media productions is relatively scarce. Apart from some insightful case studies ${ }^{2}$, critical evaluations of reality programmes are predominantly based on the analysis of media representations (cf. author removed, 2015). Such formats are, however, multi-layered and open to opposing readings (Turner, 2010: 51). Consequently, only 
focusing on the media text when addressing the motives and values of contemporary mediated performances and their effects on the participants themselves is debateable (Syvertsen, 2001).

By focusing on the participants' perspective in this study, we follow a decentred, practice-oriented approach (Morley, 2009; Couldry, 2012), asking what people do with media participation and under what conditions, what the regularities are and how agency is negotiated while engaging in media related practices. In doing so, we aim to move beyond the claims of media institutions and texts about their significance in maintaining social life, and capture, in turn, how the notion of the 'social' is constructed within the life worlds and through the actions of ordinary actors, as well as what the perceived role of media participation in this process is.

As an entry point to the complexity of these questions, we build on the notion of media ritual. For Nick Couldry (2003), this concept primarily serves to tackle how the perception of media institutions as centres of value production, and their symbolic authority based on the privilege to define and construct reality are formally acted out and naturalized through media-related practices, for example, when encountering celebrities or taking part in media productions as 'ordinary' people. However, while this perspective may provide a general framework to understand how the social position of media is re-affirmed in such instances, whether consciously or unconsciously, little is known about how media authority is appropriated by ordinary participants to generate order in their practice - in our case, to manage the act of coming out.

Our interest lies especially in this ordering work: we aim to capture how the imperatives of participating in the production reinforce and organize the protagonists' selfdisclosure. In this respect, we presume that the candidates' mediated performance is not simply a matter of displacing the act of coming out from an everyday context into the extraordinary frame of media production, but results from a more complex process of ritualization, involving the formalization and the control of the participants' behaviour, structuring the space and time of their actions, and introducing symbolic meanings to particular acts beyond the immediate situation (Coman, 2005; Couldry, 2012). Such 'basic operations' of ritualization will be traced by taking a processual approach (Coman, 2005) to the participants' experience of taking part in the production: by following their journey from the moment of their application up to the point of their self-disclosure and beyond, we shall reveal how the media involvement transforms coming out into a practice that becomes perceived as "both intrinsically different from other acts and privileged in their significance and ramifications" (Bell, 2009: 219).

\section{Interviewing the Uit de Kast participants}

To understand this process, in-depth interviews were conducted with ten Dutch and Flemish participants from all seasons of the show. By the end of the data collection, a total of twentyone episodes had been aired in the Netherlands and in Belgium and our pool of respondents 
was a good reflection of the overall composition of Uit de Kast participants in terms of age, gender, nationality and social background ${ }^{3}$. The interviews lasted from one to three hours, focusing predominantly on the motivations, experiences and the evaluations of participating in the production, but aimed at locating the journey within an as detailed life narrative as possible.

Nevertheless, getting at that point was not without difficulties, beginning with the acute problem of accessing media participants (cf. Ortner, 2010). Assuming that the production would act as a 'gatekeeper' (Syvertsen, 2001), the recruitment started by identifying and soliciting the participants via Facebook, but this method in the first round resulted in only two responses; it took approximately six months to reach additional candidates, based on the personal recommendations of previous interviewees. The initial reluctance was later explained either by the lack of trust, or by the aim of 'moving on'. Still, those who ultimately agreed to join the study explicitly aimed at recording or communicating something about their participation (e.g. "people shouldn't judge based on what they see, they didn't see the whole process").

An additional challenge was to handle and unpack the 'canned' answers of these often already 'over-interviewed' subjects (Driessens, 2015). It turned out rather soon that the candidates were quite used to critical questions about the whys and wherefores of their participation. The prevalence of three claims was especially striking: the candidates recurrently emphasized that they did not use the programme for fame, they were not forced to do anything against their will, and finally, that nothing was 'made up' for the screen. With the progress of the interviews, however, it became apparent that these narratives are not simply the means of retrospective justification: these convictions also took a significant, meaning generating role in experiencing the participation in the production as a ritual process. We shall return to these issues at certain points of the 'thick description' of the participants' journey, starting now by elaborating on the initial motivations for joining the programme.

\section{Expectations about joining the programme}

"If you are still in the closet but thinking about coming out, sign up online" - directs the presenter Arie Boomsma the prospective candidates to the programme's website at the end of the episodes. Here one can also encounter short promotional clips in which former protagonists testify to the benefits of joining. 'Manon didn't stand alone in her coming out', 'Kjeld can be much more himself', 'Kelian now lives his life as he always wanted' - announce the titles of these videos, reinforcing the premise on which the single episodes more implicitly rely: irrespective of the temporary hardships of the endeavour, the programme is able to secure a positive outcome to the self-disclosure and the participation ultimately contributes to the candidates' personal growth.

However, while several respondents underline that former protagonists were "inspiring" (typically because they were "normal people" with whom they could identify), the 
claim that the participation worked out well for others is generally not seen as a guarantee when it comes to one's own coming out: the motivations to use the programme are generally based less on the success of previous participants, but articulated more in light of the candidates' own previous failures in attempting to come out.

In this respect, the interviews reveal that the initial expectations about joining the programme commonly entail the idea that the media involvement will give a 'push' to complete the mission without backtracking. This line of reasoning also recurs in several episodes (author removed, 2015). However, while the 'push' in the media text is generally equated with the supportive guidance of the presenter, the aspirant candidates primarily conceive of it as a temporal pressure that would ultimately prevent them from procrastinating: "There is never a good moment, so I thought if I use the programme, I have to do it, I have no choice. If it is filmed, I cannot say 'no, let's do it tomorrow'" - so runs the typical argumentation. In addition, many candidates anticipate that the camera presence will provide protection in the actual moment of the disclosure: "I thought: Ok, the cameras are there so my dad won't hit me and my mum won't bitch slap me" - explains an early applicant how he pondered over his chances.

These - at this point rather short-term - considerations imply a common presumption that taking part in a media production has disciplinary affects on those being involved - and therefore, the surveillance logic of the "work of being watched" (Andrejevic, 2004) can be employed and exploited for one's own benefit as well: the camera presence is anticipated to regulate the candidates' behaviour (pressing them to finally come out and free themselves of the burden of their secret), as well as to mitigate the possible negative reactions of the environment (they will be on television and, therefore, similar to Theo's mother, they have to 'put up a smile').

Nevertheless, the application is typically not preceded by long deliberation: the candidates often question if they are special enough to be on television, and simply do not expect to be selected for participation. "I said: let's do it, they won't choose me anyway" recalls an interviewee. "I never thought that they would actually reply. I thought I was just a farmer guy. Not really interesting" - supposed another participant. Consequently, the positive reply from the production is often received with mixed feelings: "Then I started worrying: shit, what did I do. I knew they wouldn't come immediately with cameras, but still felt that damn, now I have to tell my story" - summarizes a respondent the commonly reported first reaction. "I got quite anxious, but also felt happy that they wanted to use me, and that they wanted to help me. But honesty, I had no idea how I would be able to do it" - admits another candidate.

The above examples show that as soon as the utilization of the programme turns from a theoretical possibility into a realistic prospect, the applicants generally become insecure about what they have signed up for. Still, in spite of their initial doubts, the candidates continue their journey without cancelling their participation ${ }^{4}$, even when the stakes are getting higher. What keeps them moving during the process of the production? In the following sections we look into what factors actually 'push' the candidates towards 
performing the disclosure and what experiences of taking part ultimately contribute to their determination to 'tell their story'.

\section{Submission to the imperatives of media production}

Being a 'participant' of a television programme is not something that ordinary people instantly do when getting into a media production. Rather, as argued by Ytreberg (2004), participation can be seen as a trajectory from the initial contact until the actual performance, which prepares non-media professionals to conform to the requirements of the format and the order of production. In the case of Uit de Kast, this 'process of formatting' (ibid) lasts several weeks, sometimes even months. However, the candidates generally perceive this period as going by very fast, leaving little room for hesitation.

During the preparatory phase, the candidates are kept rather busy with the very downto-earth, logistical aspects of the shooting: they need to find suitable dates, and have to come up with a realistic 'cover story' that fits with their life circumstances, while also concealing the real reason for filming. Both tasks require a considerable amount of effort from the participants: "I wanted to do it in the sports club and with my friends separately, but if they post something on Facebook or Twitter after one part is done, there is a chance that the other group will also read it. Then I had to think when to go to my parents..."- describes an interviewee the challenges of the planning. Furthermore, the cover story must convince the environment that there is, again, something extraordinary in the candidate worthy to show on TV, without immediate associations to the programme ${ }^{5}$. Composing such pretexts demands discretion and some creativity; the lack thereof may endanger the entire mission, as shown by the following situation: 'I told to my friends that the filming is about math students, but one of them became suspicious: 'Aha, mathematics. What's so important about mathematics? And why should they choose you if there are thousands of people studying mathematics?' She already thought what was going to happen, so she didn't show up that night. Later she said she didn't want to ruin it for me.'

The preoccupation with such challenges delivers a certain alienating, yet at the same time 'therapeutic' effect, as long as the logistical pressures of the production constantly distract the candidates from the existential stakes of their forthcoming performance. As one of them admits: "I was busier thinking 'what's next, what's next', than worrying about what my parents would think". This neutralization generally culminates with the actual arrival of the production team for the shooting of the first, 'introductory' scenes. This is the moment when many candidates realize that quite a few people have been mobilized "only for them", and that being at the centre of the production demands a quick acquirement of the rules of performing for television.

During the 'warming up' shots the candidates have to learn how to "act normal" in the presence of the camera. Mastering the competencies of media participation furthermore requires compliance with the technical necessities of the shooting, which becomes especially crucial in the actual moment of the coming out. "You have to ignore the cameras, but you also 
have to wait for the sign when you already have enough to show. Because if you just say ' $\mathrm{Hi}$, I have to tell you something, I am gay', they just have three minutes of filming" - asserts a candidate, testifying also to the 'expertise' the participants often and enthusiastically claim to have gained about what is "part of television making".

Nevertheless, the fascination and the preoccupation with the formal, 'behind the scenes' imperatives of media production is but one aspect that pushes the candidates further and further. The interviews reveal that the cooperation with the crew in delivering enough filming material and the desire to perform the task 'professionally' have an affective dimension as well. When talking about their journey, the candidates without exception emphasize the strong emotional connection that developed with the crew during the process. The respondents constantly emphasize that the production members "didn't just do their jobs", but showed support and empathy all the time, even after the shooting was done: "They didn't simply walk away but stayed with us for hours. My parents also appreciated that it was not like that they made the shot and then they leave. They were showing to my parents that they understand and know how hard it is now, and support them as human beings" -a candidate attests to the attentiveness of the crew, with some defensive overtones.

Whether or not the development of such an affective bond is part of the production's strategy to maintain 'ordinary' participants' commitment to the process (cf. Syvertsen, 2001; Grindstaff, 2009), many candidates indeed feel that the emotional support given by the staff should be reciprocated. As a result, by the actual time of the disclosure the coming out often becomes seen also like a personal obligation towards the production team: "They put everything into me, so I couldn't disappoint them by not saying it" - argues a respondent. "I didn't want to let down all the people working for the programme. They have nothing if I don't come out" - demonstrates another account how coming out becomes perceived as a duty dictated by the sense of comradeship with the crew members.

This development already indicates that the motives for coming out with the programme become gradually reorganized during the production process: while the act of joining Uit de Kast is about seeking help in taking the life changing step, the actual act of the disclosure is also facilitated by the desire to please the crew and comply with the imperatives of television making. An overall shift in the priorities is especially perceptible in those rare instances when the parents become suspicious about the real reason of the filming: "My mom asked me two weeks before the camera came: did you apply to Uit de Kast?" - recalls a participant - "So I had to lie to her: no, please no. Why do you even think of that? It was really hard, but she finally believed me".

One may wonder: why does this candidate, instead of making the confession at this point, continue with the production, even if the involvement of the cameras would not even be necessary anymore? While the desire not to let the crew down may play a role in this persistence, other developments during the process also contribute to the candidates' resolution to complete the mission with the media. The interviews reveal that aside from the push given by the logistical and interpersonal pressures, the journey also entails the participants' gradual discovery of their own agency, as well as a growing sense of 
empowerment concerning their own ability and chance to represent and change social reality. In the following sections we elaborate on what factors add to these developments and what role they play in the construction of the candidates' coming out experience, as well as the perceived value of their participation.

\section{From submission to symbolic empowerment}

Previous research indicates that getting into a television production is not necessarily a liberating affair. For instance, Shufeldt and Gale's study with home makeover TV cast members (2007) reveals that participants often realize that they have ultimately no real control over the events involved in the process, and consequently, their agency is felt to be diminished while taking part. The narratives of Uit de Kast candidates, in turn, bear witness to a reverse experience: what starts as a voluntary submission to the authority of media production, evolves into a strong sense of playing an active and important role in shaping the programme. In this respect, three common and interrelated developments shape the participants' experiences, which not only reinforce the notion that the candidates stand behind the cameras as much as performing in front of them, but also play a substantial role in performing their coming out.

\section{Refiguration of the 'ordinary' self}

Partly to reflect on allegations of appearing on screen for fame, the participants often emphasize that in spite of having been on television, they remained the same 'ordinary' persons. Still, other layers of their accounts imply that the candidates, with the advance of the production, discover 'extraordinary' factors in themselves which are worth showing on TV.

One of the remarkable developments in this respect is the emerging certainty that the supply of suitable applicants is not as ample as the ongoing popularity of the programme suggests. "They [the production] had a lot of fake people, a lot of gay people who were already out of the closet but applied just to be on TV. The crew told me. They had many fake people, while it was hard to find real people" - asserts a Flemish candidate, framing himself this way not only against self-appointed celebrities, but also justifying his uniqueness with the scarcity of authentic - i.e. genuine - candidates like him. An increased sense of self-esteem is furthermore reinforced by the realization of the value of 'ordinariness' for the purposes of the programme, as long as it speaks for, or gives voice to a specific group within gay youth. Compare for example, how the Dutch candidate, who formerly considered himself 'uninteresting', becomes aware of his representative significance and revises his thoughts with the advance of the production: "In the beginning I was like: I'm only a farmer guy. But when they were telling me that they wanted to show that homosexuality is everywhere in the country, in every age group, every ethnic background, I started thinking: maybe it's very hard to find a farmer guy. So I really felt I might do this, to show to people: I come from a farm and 
I am gay. But that feeling grew with the process. I just signed up on a whim and without the idea that I would be selected to be part of it."

Notions of exceptionality not only emerge in relation to such personal attributes and circumstances, but also recur in the participants' evaluations of the unique features of their journey vis-à-vis other protagonists. Although all the episodes follow the same ritualized structure, the respondents commonly assert that their episode is somehow different from the rest, and maintain that they carried out their coming out 'in their own way': "By telling it in the sports club as well, I was the only one who did it three times. Most of them did it only twice" - underlines an interviewee. "Nobody did it in front of such a large public" emphasizes another participant. This preoccupation with the distinctiveness of one's own coming out is often also manifested in the inclination to highlight the success of the end product: "The producers said that my episode had almost one million viewers... while others only had 300,000" - remarks another interviewee, who otherwise also cautiously communicates that gaining popularity by no means motivated him before or during his participation.

The emphasis on the lack of such motivations, however, does not necessarily contradict the prevalence of the above claims. Rather, the constant differentiation between one's own episode and the rest can be seen as a means of validating the candidates' actual choices, actions and their overall role in the production process. This urge becomes especially clear in the light of another development during the participation: an increasing sense of being the actual owner of the episode and a co-creator of the programme.

\section{Emerging sense of (co-)authorship}

Contrary to their initial expectations about simply 'going with the flow' of the production, the candidates, as we have seen, have a share in designing the conditions of their coming out at an early stage, reinforcing the notion of being an active agent in the production process. "I felt like I became part of it. Instead of they telling me what to do, they were asking me what I wanted to do and how" - explains an interviewee how his freedom to make choices made him feel responsible for the production as a whole.

Making decisions, however, is not confined to the purely logistical aspects of the shooting, but also concerns more substantial questions of representation. In this respect, the participants often realize that certain arrangements also provide them an opportunity to frame themselves in a particular way: "I could make up an activity, and paintballing was something tough. And it was something I wanted to show: I am not a pussy. I might be gay, but I'm still a normal guy". With this involvement in staging their performances, the participants commonly start conceiving themselves as the primary authors of their episodes. "I was basically the director" - asserts a respondent - "it was really in my hands." "I was actually the one giving them instructions... if they could film things or not, if they can use it or not" - attests to another participant's strong sense of having control over the representation of his coming out. 
Sometimes, nonetheless, certain fractures do emerge between the vision of the crew and the participants, and the treatment of such instances shows a definite shift in the perception of the power relations underlying the production process. "I told them that I don't mind telling my story on television, but it has to be my story and not their story. Fortunately we were quite on the same path. Sometimes we weren't, but then I knew I was in control, because I could blow off everything. (...) I want to do it there, on that date. If you don't agree, then I'll do it without a television programme" - asserts a candidate. Note here again how the emerging confidence overwrites the initial reasoning about participating in the show as the ultimate and only option for coming out: if you do not play according to my rules, I will reveal my secret alone, without the involvement of the media. This demand also suggests that the support potentially given by the programme becomes of secondary importance to the candidate compared to the infrastructure it provides to tell his 'own story'.

The 'stories' of the protagonists indeed vary to a certain degree, yet their core message, and more importantly, the drive to tell them is constructed and facilitated by the same principle. This leads us to a third common development during the production process, entailing the gradual internalization of the values for which the programme more generally stands, and the subsequent realization of the public benefits of performing the disclosure in front of the cameras. In the following section we will look into how these factors ultimately turn the coming out from a personal endeavour into a societal mission.

\section{Embracing the 'social': the reinterpretation of coming out as an emancipatory project}

As previously mentioned, orchestrating the coming out as a mediated performance often becomes seen as a means of self-authentication. However, the participants' desire to prove something about themselves through the public display of their coming out is just one side of the story. While the journey generally starts with individualistic considerations, it typically ends with a clear vision of the societal importance of the disclosure.

In this respect, the core 'message' the candidates most commonly want to convey is that "being gay is not a choice", often linking this tenet to the hardships resulting from their particular circumstances. "I wanted also to show the girl side (...) that it is also hard for girls to tell it to friends and to feel accepted" - points out a female candidate. "I wanted to show how my religion conflicts with homosexuality" - relates another respondent the "born this way' principle to the challenges of negotiating with his intersecting identities.

With all their essentialism, the above claims not only demonstrate the espousal of the programme's mission to promote visibility, acceptance and tolerance, but also correspond with the candidates' evolving conviction that their coming out will help others who are going through the same struggle. For many participants, the pursuit of the greater common good also overwrites the initial motive for joining: "I figured: no matter what the outcome is for me, I will make a difference, maybe in someone else's life" - concludes a participant, interpreting his disclosure ultimately as an altruistic act. Furthermore, this reconsideration of coming out as a social sacrifice often also serves to transcend the moral dilemmas incurred by dragging 
parents into the production without their previous consent: "I felt bad because of the lie, and I knew that going there with the cameras is like attacking them. But I felt responsible for doing this. I thought it sends a message to Dutch civilization, or how do you call that... society" argues a respondent.

This justification also recurs in other candidates' retrospective evaluations: "Yes, it is something private. But I think the whole cast can inspire people. Still now, I get reactions like I came out of the closet because of you"-maintains a Flemish respondent. Still, while these transcendent motives may play a role in facilitating the coming out, and the audience reactions might justify the public performance, these aspects matter little when the shooting finally ends. The 'awakening', both in a figurative and a literal sense, is commonly described as a challenging experience: "The crew stayed long at night. And waking up next day, knowing that my family is outside... I simply didn't know how to open up the door of my room" - recalls a participant. What happens after the cameras and the crew are not there anymore to provide support? Before concluding, we briefly look into the candidates' journey back to their ordinary life, by highlighting some aspects of the afterlife of their disclosure.

\section{Beyond participation}

The ordering work of (media) rituals does not end when they are completed (Couldry, 2012: 77), but continues to exert its power even beyond the actors' mediated performances. Following the shooting, most participants feel pressured to keep on coming out to all the people who matter in their wider environment: "I did not want them to see it on TV before I told them. I also didn't want to be always busy with guessing who knows and who doesn't after it is aired" - hence the typical argument. "I was still trying to postpone it as much as possible, but finally I told my wider family a few days before it was actually shown on TV" another account demonstrates the organizing role of the forthcoming publicity by setting the time for the candidates' subsequent, face-to-face self-disclosures.

Getting on air, however, is not always self-evident: parental consent is often hard to obtain. After the crew is gone, the candidates are commonly faced with reprehension. "My dad was mad. Not because I am gay, that is not an issue. But because of the cameras. He said that I could have just simply told him. It's not a problem, so why the camera" - recalls a respondent, and the father's reaction is relatively mild here. The choice of using the programme triggers a variety of emotional responses from the parents: feeling betrayed, not being trusted, and last but not least, guilt. The reconciliation work is often lengthy and traumatic, sometimes involving weeks of crying and fights about the forthcoming broadcast. In the light of these developments, the value of participation sometimes becomes questioned by the participants: "When I was making the programme, I didn't realize what I was doing. It just felt right. But after it was shot, I became insecure about it. I didn't want things to blow up, I just wanted to be someone normal, and I wanted to show that I am normal. But when you do it this way, you don't make it more normal. Just saying it is more normal then making a programme out of it" - concludes a female candidate. 
In the end, however, the parents most of the time agree to the broadcast. Paradoxically enough, it is often the end product that brings the reconciliation forth: "I realized that my parents didn't have a clue. So I called KRO that I want a DVD with all the movie fragments of me until then. Because then I can show them what the idea behind the programme was. (...) And then they saw me talking about my homosexuality and how I lived it. And then they thought we should do it" -a candidate recalls how the recordings demonstrating his many years of struggle ultimately convinced his parents to take part.

The episodes are sometimes already available on the internet before actually shown on TV, but many candidates wait to watch them together with their friends and families; this has an additional, symbolic significance for the ultimate closure. "They all came to my place. They felt it was a good episode. But mostly they were just like 'oh, is my hair really like that?' And I was doing the same. And my dad was joking all the time: oh, that's a nice man, who is it? Oh, that's me" - describes a candidate how the sometimes opposing stances towards the entire process become mitigated by the shared reaction to 'being broadcasted', underlined by the playful enactment of the extraordinariness of appearing on the screen as 'ordinary' people.

Thus, the endeavour commonly turns out well, and the encouraging reactions from the audience also seem to justify the candidates' choice - at least on the surface. For some respondents, the overall evaluation of the journey remains somewhat ambiguous, even years after the actual disclosure. For instance, near the end of our conversation, Theo ponders about the difficulties grasping the real nature of his parents' agency concerning their consent to the broadcast, a question which he was left alone to deal with: "They said to me: okay, we'll do the program, because we think it's a nice episode. But up till now I'm still not sure if this was the real reason... they might have cancelled it if it was not their son. But I never asked them. It's not like we can't talk about it anymore, but I don't want to talk about it because then my parents start crying again, and I really don't like that. Sometimes I feel bad about my decision, but then I tell myself that if they didn't want to join in, they had the possibility. But then I think: no, they didn't have the possibility, because they needed to support their son. Do you understand? If you ask me now if I would do it again, I do think so. And I hope if you ask me in ten years I would say the same. I hope so. But I can't see into the future."

\section{Conclusion}

In this paper we addressed how coming out as a mediated practice is experienced by the protagonists of Uit de Kast, and what assumptions about media participation motivate them before and during their taking part in the production. As we demonstrated, the cameras are indeed 'there for a reason', yet the reasons given by the respondents are substantially different at the beginning and the end of the process. In their attempt to carry out their coming out without backtracking, the candidates choose to perform their disclosure within a formal, obligatory procedure, and therefore, voluntarily submit themselves to the rules and logics of media production. However, while remaining submissive, a sense of being powerful 
is also needed: the candidates' discovery of their representative significance, the perception of their role as co-creators of the show, and the internalization of the societal mission of the programme while socializing into the world of media production all add to this emerging sense of empowerment, which, as we have seen, sometimes even overwrites the initial purpose of joining: the individualistic enterprise of coming out turns into an emancipatory project.

Of course, there is the question to what extent this agency to 'tell my own story' and the societal values embedded in these ritual confessions are reinforced by the crew as a strategy of 'manufacturing consent' (Cottle, 2006). Still, according to the experiences of the participants, the notion of being in charge, and the perceived symbolic power implied by being actually the one who stands behind the camera is an essential aspect of the journey. After all, this is the 'push' given by the programme: you have to do the coming out, because the means of constructing and changing social reality is now in your hands.

In this respect, the perception of the 'social' underlying the motives of using the programme goes through a remarkable transformation as their participation in the production proceeds. While the original promise of Uit de Kast is to help the candidates through a critical phase of their lives which involves deep existential fears about the disruption of their immediate social worlds, the participation in many cases ends up harming these primary relationships - exactly because of the involvement of the media. As they start considering themselves potential agents of helping others by showing the challenges they face, the candidates often consciously take this risk as a sacrifice for a 'transcendent', greater common good. In this sense, the 'myth of participation' that organizes the motives and experiences of the candidates throughout their journey is ultimately based on the notion of social responsibility, emancipation, and the idea that 'ordinary people' can change the world through taking part.

Although one may assume that it is the domain of social media where this myth is most prominently acted out and naturalized, it is striking how intensively television, still as a dominant medium (Schäfer, 2011), has been involved in maintaining and pushing it forward in ritualized forms. Similarly to Uit de Kast, recent programmes like the Dutch Over mijn lijk ('Over my Dead Body'), which follows young people with a terminal illness, the anti-bullying reality Over de streep ('Challenge Day'), or BBC's Undateables address and confront the audience with existential and socially pressing issues, while also suggesting a gradual integration of 'social media logic' and its premise to provide voice to ordinary people into the existing mass media logic of (public) broadcasting (van Dijck and Poell, 2015).

While the evaluation of these developments can proceed further along different routes, the concept of ritual may continue to remain an important point of orientation. As Couldry argues (2012), rituals generally operate on the basis of the human need for order, yet media rituals, instead of fulfilling such a basic function, serve to justify the uneven distribution of symbolic power. At the dawn of web 2.0 it was presumed that media's ritual power, reproduced by the restricted access to the means of defining reality would gradually dismantle due to the emergence of more democratic forms of media participation and production (Couldry, 2003). However, the Uit de Kast phenomenon signals a reverse 
tendency. The idea that emancipation and the improvement of the social world can be achieved through participating in productions like Uit de Kast seems to work as an effective means of (re)confirming the ritual power of central media and sustain their privileged position against the dispersed and often casual practices taking place on (seemingly) more grassroots platforms. The experiences of Uit de Kast participants also tend to confirm this trend of remaking media rituals for the age of participatory media culture. At least, the motives and assumptions of our interviewees concerning their journey suggest that (central) media rituals are becoming increasingly expressive to human needs for order, to define the social and its core values, and at the same time, to symbolically mark, recognize and designate someone's place in the world.

\section{References}

Andrejevic M (2004) Reality TV: the work of being watched. Rowman and Littlefield Pub.

Bell C (2009) Ritual Theory, Ritual Practice. Oxford: Oxford University Press.

Coman M (2005) Cultural anthropology and mass media: a processual approach. In:

Rothenbuhler EW and Coman M. (eds) Media Anthropology. Thousand Oaks: SAGE, 46-56.

Cottle S (2006) Mediatized rituals: beyond manufacturing consent. Media, Culture \& Society 28(3): 411-432.

Couldry N (2003) Media rituals: A critical approach. London: Routledge.

Couldry N (2012) Media, society, world: Social theory and digital media practice. Cambridge: Polity Press.

Curnutt H (2011) Durable participants: A generational approach to reality TV's 'ordinary' labor pool. Media, Culture \& Society 33(7): 1061-1076.

van Dijck J and Poell T (2015) Making public television social? Public service broadcasting and the challenges of social media. Television \& New Media 16(2): 148-164.

Driessens O (2015) Expanding celebrity studies' research agenda: theoretical opportunities and methodological challenges in interviewing celebrities. Celebrity Studies 6(2): 192-205.

Dovey J (1998) Freakshow: First person media and factual television. London: Pluto Press.

Grinstaff L (2009) Self-serve celebrity: the production of ordinariness and the ordinariness of production in reality television. In: Mayer V, Banks MJ and Caldwell JT (eds) Production studies: cultural studies of media industries. New York: Routledge, 71-86.

Grindstaff $L$ (1997) Producing trash, class, and the money shot: a behind-the-scenes account of daytime TV talk shows. In: Lull J and Hineman S (eds) Media scandals. New York: Polity Press, 164-202.

Hobart M (2010) What do we mean by 'media practices'? In: Bräuchler B and Postill J Theorising media and practice. New York: Berghahn Books, 55-76.

Kuppens A and Mast J (2012) Ticket to Tribes: culture shock and the 'exotic' in intercultural reality television. Media, Culture \& Society 34(7): 799-814.

Morley D (2009) For a materialist, non-media-centric media studies. Television \& New Media 10(1): 114-116. 
Ortner SB (2010) Access: Reflections on studying up in Hollywood. Ethnography 11(2): 211233.

Schäfer MT (2011). Bastard culture!: how user participation transforms cultural production. Amsterdam: Amsterdam University Press.

Shufeldt M and Gale K (2007) Under the (glue) gun: Containing and constructing reality in home makeover TV. Popular Communication 5(4): 263-282.

Syvertsen T (2001) Ordinary people in extraordinary circumstances: a study of participants in television dating games. Media, Culture \& Society 23(3): 319-337.

Swidler A (2001) What anchors cultural practices. In: Schatzki T, Cetina K and von Savigny E (eds) The Practice Turn in Contemporary Theory. London: Routledge, 74-92.

Turner G (2010) Ordinary people and the media: The demotic turn. London: Sage.

Ytreberg E (2004) Formatting participation within broadcast media production. Media, Culture \& Society 26(5): 677-692.

\section{Notes}

\footnotetext{
${ }^{1}$ The most eye-catching example of this trend is the constant production of coming out clips on YouTube, some of them with over ten million views. See for instance https://www.youtube.com/watch?v=L3KOCJ8usPU, accessed on 19 April 2015.

${ }^{2}$ See for example Grindstaff's work on daytime talk shows (1997), Syvertsen's study of television dating games (2001), Shufeldt \& Gale's ethnographic research into home makeover reality shows (2007) and more recently, Kuppens \& Mast's multi-actor analysis of intercultural reality programmes (2012).

${ }^{3}$ The majority of the interviewees are higher educated and male ( 8 out of the 10), aged between 18 and 30 , living in different regions of the Netherlands and Belgium, including candidates from different religious denominations and different ethnic backgrounds. Although not requested by the respondents, the quotes have been anonymized in most cases to protect the identity of those participating in the study.

${ }^{4}$ This option is left open during the course of the journey: contractual agreements do not bind the candidates in this respect. Some candidates explain this by the assertion that the entire process was based on trust, while others with the initial lack thereof: "If I had needed to sign anything, then I wouldn't have participated. I was all alone and I didn't have the opportunity to talk to anyone about my rights".

${ }^{5}$ Due to the same considerations, the presenter does not appear on the scene until after the actual disclosure from the second season on.
} 